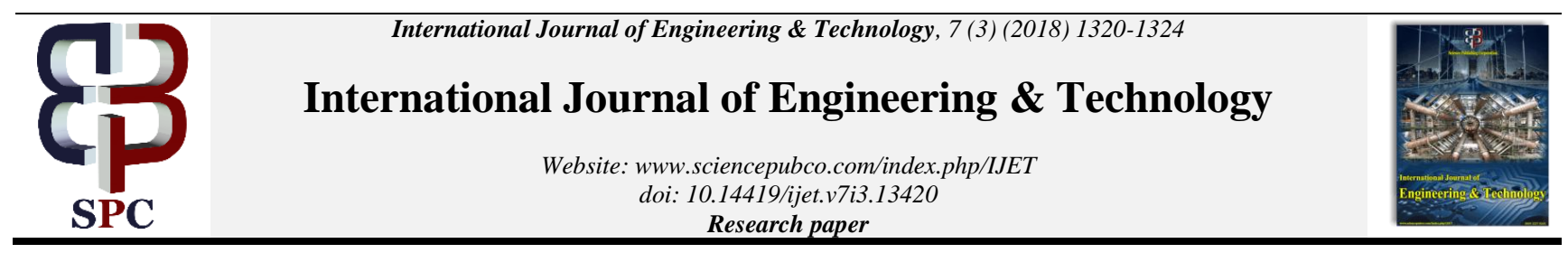

\title{
A Structural Equation Model for Emerging Needs and Changing Role of Social Media Usage as Financial Service Platform
}

\author{
Prof. Shrikant Waghulkar ${ }^{1}$, Dr. Nitesh Behare ${ }^{2},{ }^{*}$ Dr. V .P Sriram ${ }^{2}$, Prof.Anup Shivanacheri ${ }^{1}$ \\ ${ }^{1}$ Assistant Professor, Balaji Institute of International Business (BIIB), Pune, India \\ ${ }^{2}$ Associate Professor, Balaji Institute of International Business (BIIB), Pune, India \\ *Corresponding Author E-mail:dr.vpsriram@gmail.com
}

\begin{abstract}
In this Modern Era, the Major usage of social media is changing its old traditional mainstream from entertainment to the world of opportunity to work and trade. In the Emerging banking industry where customers' interaction plays a major and necessary role, Now a days, these digital communication is becoming a Predominant and strong communication channel between Customers and financial institutions Digital Medias are considered as the most valuable tools for potential customers or clients get connected to the bank towards accessing their financial services in a most fashionable manner. Hence, the Emergence of Social Media as a major digital Platform which plays a major and replacing traditional way of getting financial services to a most modern way of accessing such financial services and its related information. In this paper, the researcher tries to portray the emerging importance of social media as a technological innovative platform which in turn plays a major role in Digital Banking and its related services. One way the researcher tries to bring the growing importance and need of these social media as innovative technological platform readily developing in banking sector where in customer could be able to access and do financial transactions in a most simpler and economical manner.
\end{abstract}

Keywords: Social Media; Financial Services; Digital Banking; Etc.

\section{Introduction}

Social Media - A technological boon of Twenty First Century which helped many businesses to overcome from customer centric challenges. As per Experts from 2015 to 2017, Indian social media users were increased from 142.23 million to 196.02 Million i.e. approximately $27.44 \%$ growth and it will reach up to 370.77 million by 2022 . Whereas number of mobile phone internet users in India in 2015 was 259.88 million and expected to grow 511.89 million by 2022 . This given statistics suggests us about the business opportunities and customer focused services for the Financial Institutions.

Social media is, and will be, the undisputed king of the Internet in India. As per the study of KPMG on the Social Media on Financial Services, Sunny Banerjea [1] reveals that like other industries, banks have enormous unexploited opportunities to monitor social networks, analyze trends, and engage with customers to create relationships .For customers, Social media is a great way, to deepen relationships and learn more and more about financial institutions. Many of the tomorrow's winners of connected enterprises will be decided by the emerging platform of Social Media.

In the area of financial services, Customer's queries and complaints can be resolved by interacting through the social media. When the queries and / or complaints have been posted by the customer on the company's/ institution's social media page, the representative of the financial institution can address it in a timely manner. The financial institution may contact the customer directly by using a secured channel of communication if the activity requires any exchange of sensitive information. This initiative has resolved many queries and at the same time, it saved many direct and indirect cost of the company. Today, financial institutions, all over the world, are working desperately to develop the Connected Customer Strategy. Sunny Banerjea ${ }^{[1]}$.

As India is having huge internet as well as social media users, this is undoubtedly a segment that represents in many ways the future/prospective customer. The relevant financial institutions will have to develop an interaction strategy and a channel which address the needs of miscellaneous set of customers with their own set of preferences and demands. Financial institutions will be able to design their own interaction strategies with both their current and future customers just by understanding the forces underlying social networking interaction.

Social media defines the customers preferences, their choices, their demands, be it Twitter, LinkedIn, Face book, Hike etc. - The endless amount of available data allows the financial institutions to design customer's profiles with a level of detail which would have been unthinkable even a couple of years ago. Advanced Data Analytics techniques, abundance computing power, economic data storage, advanced data search and scanning competencies will allow financial institutions to offer customized offer rather than generalized one to their existing as well as prospective customers. This will help our financial institutions to take customer satisfaction and delight to new levels provided their underlying operating models can keep right pace.

It is necessary for the financial institutions to foresee the usage of social media as a very significant tool. Financial institutions should focus on diverse needs of their customers and their employees from innovations, previous experiences and delight perspective so as to provide various financial services, while taking care of the security and trust of the customers. 


\section{Literature Review}

On $8^{\text {th }}$ Nov 2016, Prime Minister Mr. Narendra Modi, announced demonetization of all the 500 and 1000 Indian currency notes which has drastically harmed the Traditional Indian Payment Ecosystem. Aim of this demonetization was to curb black money and also give a push to the Digital Payment Ecosystem, from which many enterprises woven around the digital payment Economy got a massive boost. In the very short span of time, demonetization has led to the rapid adoption of digital payments i.e. e-wallets, and credit \& debit cards as a means of payment. Similarly it was a great opportunity for various giants of Social Media to jump into the new business by providing additional services like banking and financial services. Sourav Mujumdar ${ }^{[2]}$.

Richard Eldridge ${ }^{[3]}$ Social Media is transforming customer's banking relationships in a very significant way from improving customer care services to allowing users to send money to others through online platform. Financial Institutions are using social media data to help their customers in getting access or even opening a bank account and other banking transactions. Banking envi- ronment is changing so rapidly, where it is possible to claim that social media platforms may be the Future Banks of India.

In earlier stage of Social Media, it was considered to be the place where people of similar interest get connected and share their thoughts. Social Platforms, such as We Chat and Viber in Asia as well as the global powerhouse that is Face book are gradually providing a broad range of services to their users either directly or through partners. Even few months back Face book Messenger has started assisting in banking and financial transactions through Live Chats.

According to following data graph (Fig 1), such a high levels of social media penetration, use and engagement of the users have meant that financial institutions are started to recognize the opportunities that social media can bring to their businesses. They are looking forward to take a competitive advantage over other institutions while also trying to mitigate the threats posed by social media, such as when people share highly sensitive information publicly.

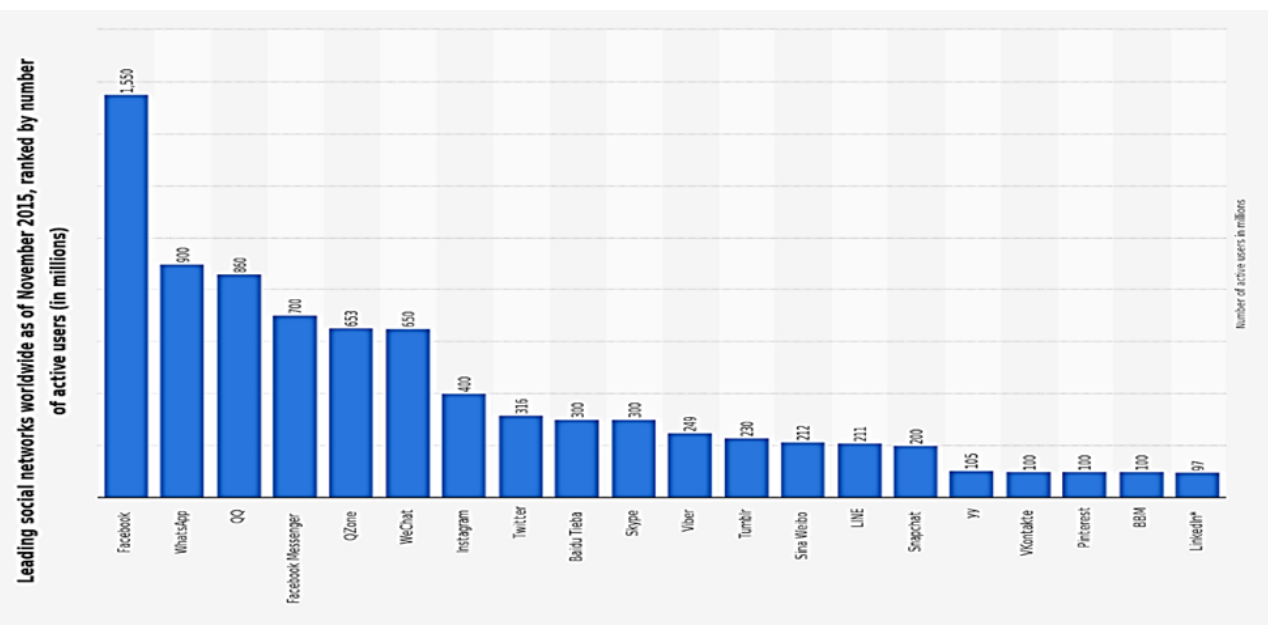

Fig. 1: Source: Https://Www.Weforum.Org/Agenda/2016/04/How-Social-Media-Is-Shaping-Financial-Services.

A new industry, Financial Technology (FinTech), is emerging as a fastest growing industry which is incorporating company that use modern technology to make financial systems more efficient and sound. According to the report by Accenture and the Partnership Fund pointed that "Global investment in FinTech ventures has tripled from around $\$ 1$ billion in 2008 to nearly \$3 billion in 2013". Most of these companies are revolutionizing the traditional business models by using social media on which financial sector has relied upon. Richard Eldridge ${ }^{[3]}$

According to Laurence Leyden ${ }^{[4]}$ in recent years financial industry has suffered consecutive blows. Worldwide banking crises, new banking regulations, empowered customers calling the shots, not to mention a new breed of digital disruptors out to steal market share, have wreaked havoc on business as usual. And because of that reputations has been damaged, profits has been reduced and management has been blindsided. The only way to way forward is reengineering i.e. changing a business model, change of the mindsets and change in the financial ecosystem of the financial institutions. It was a social media, who has given new and ideological way to transform banking and financial transactions to new heights. It helped in uplifting major issues in all aspects.

According to Laurence Leyden ${ }^{[4]}$ in less than a decade, the daily business will be done from anywhere at any time on mobile devices. All services need to be adjusted to these demands and be available accordingly. Due to security, compliance, and risks reasons, the majority of banks have made a pass through on this communication channel so far but social media allows banks to connect with their customers in a completely new manner. Many banks and financial institutions have already started using social media for their services. Whereas some are focusing on providing infor- mation about products and trying to generate leads, others are providing transactional services.

According to Angloher - 2017 recent growth and interest in social media is driving banks to learn more about the various social platforms available to them and to consumers and how networks like Face book and Twitter can assist them in;

- Engaging with their customers, stakeholders, and employees

- Enhancing their brand by connecting with consumers

- Distinguishing themselves from their competitors

- Reducing costs seeing as these social media communication channels are relatively low in cost when compared to the amount of customer satisfaction produced in comparison to the more traditional methods

- Boosting innovation by learning who the consumer is and what they want and then creating products that will serve those needs;

- Increasing revenue.

Many experts argue that, due to lack of human interaction and human interface, digital banking has made customers feel more distant from their banks. So instead of interacting with a teller at a bank, customers can do most of their financial and banking transactions through mobile. Social media has provided a way where companies can connect their customers at personal level. Now a day's financial service sector are using various social media platforms to create the value that was once found physically in their branches. For example, through their Face book page, a bank may post a snapshot of one of their employees with a brief blurb about his/her job duties and values. 


\section{Objectives of the Study}

- To study the feasibility for financial transactions through social media platform.

- To study consumer perception for financial transactions through social media platform.

- To study acceptance of social media for financial transactions.

\section{Hypothesis of the Research Study}

$\mathrm{H}_{1}=$ Financial transaction through social media are feasible according to current available technology and knowledge of social media users. $(\mathrm{H} 0=\mu>3)$

$\mathrm{H}_{2}=$ Social media users have positive perception about safety and trust of financial transaction trough social media. $(\mathrm{H} 0=\mu>3)$

$\mathrm{H}_{3}=$ Acceptance score of financial transaction through social media platform is dependent of feasibility and perception of social media use.

$\mathrm{H}_{4}=$ Frequency of financial transaction through social media platform is dependent of feasibility score and perception score of use.

\section{Research methodology}

Exploratory Research Design is used in this research study till the formation of research objectives and hypotheses as it is not possible for researcher to set objectives and hypothesis without the analysis of existing body of knowledge. Descriptive research design have played major role in this study to justify the objectives and to test the acceptance or rejection of hypothesis. As this research was a qualitative research till the time of objective and hypotheses formation and then quantitative to test the hypothesis, this research is the combination of exploratory as well as descriptive research. For qualitative study various types of technology related research journals and books were used.

Internet has played major role as source of secondary data. Structured questionnaire was circulated to sample respondents which were prepared to measure the acceptance level of respondent for measurement variables affecting dependent variable. Nonprobability sampling was used in this research as young people are targeted as respondents from four different regions of India. It was not feasible to define this population in terms of number of total respondents and hence, non-probability Quota sampling was used. People in age group of 18-45 were considered as classes of respondents for this study under focused group study method. 200 emails were sent to respondents from each region for which e-mail addresses were collected from friends and their references as wel as with the help of Google contacts. Pilot study was performed on initial 25 responses of survey to measure reliability of survey instrument and instrument is found reliable with 0.775 Chronbach's alpha value. 445 respondents have given their opinion through survey out of 800 surveyed e-mails and hence 422 samples were taken into consideration for final study with convenient sample design. All independent variables were measured on five poin Likert scale for respondents opinion and demographic factors of respondents were measured on Nominal and Ordinal scale. SPSS software is used in this research to perform parametric tests like ttest, z-test, correlation, regression and AVOVA on collected respondents. AMOS is also used to perform structural equation modeling.

\section{Limitations of the study}

This research paper was limited in its analysis to the selected respondents. Thus, by the time this paper is completed, there may be some information missing or not considered here, even though it might be recognized as information brining in new and important ideas to the topic. This research paper is based on the personal experience of the respondents. As this research paper is related to user's interface with the current available technology, that technology may get updated or changed from its available version. Finally, limitation was presented by the short time period on hand and the allocated space that this paper had to follow.

\section{Data analysis and interpretation}

\subsection{Reliability analysis}

Variable Definitions: Feasibility, Perception and Acceptance are considered as dependent variables in this study which are measured with the help of measurement variables as given below:

Table 1: Measurable Dependent Variables of the Study

\begin{tabular}{|l|l|l|}
\hline \multirow{5}{*}{ Feasibility } & FF1 & I own a compatible device with Social Media Access \\
\cline { 2 - 3 } & FF2 & $\begin{array}{l}\text { I am aware that I can do financial transaction } \\
\text { through social media }\end{array}$ \\
\cline { 2 - 3 } & FF3 & $\begin{array}{l}\text { Financial Transactions through Social Media are } \\
\text { affordable }\end{array}$ \\
\hline \multirow{5}{*}{ Perception } & FF4 & $\begin{array}{l}\text { I am comfortable in using online platforms for Fi- } \\
\text { nancial Transaction }\end{array}$ \\
\cline { 2 - 3 } & PF1 & $\begin{array}{l}\text { Financial Transactions through Social Media are } \\
\text { safe and trustworthy }\end{array}$ \\
\cline { 2 - 3 } & PF3 & $\begin{array}{l}\text { I believe, purpose of social media is entertainment } \\
\text { and should not be used as Financial Transaction } \\
\text { Platform }\end{array}$ \\
\cline { 2 - 3 } Acceptance & PF4 & $\begin{array}{l}\text { I would like to do my financial transactions through } \\
\text { social media. }\end{array}$ \\
\cline { 2 - 3 } & AF1 & $\begin{array}{l}\text { I frequently do transaction using Net Banking / } \\
\text { Mobile App / Mobile Wallet etc. }\end{array}$ \\
\hline \multirow{5}{*}{ AF2 } & $\begin{array}{l}\text { I would like to use social media for financial trans- } \\
\text { action }\end{array}$ \\
\hline
\end{tabular}

The Above variables are measured on five point Likert scale for the agreement of respondents where 1 being strongly agree, three is neutral opinion and 5 being strongly disagree. Factors measuring feasibility, perception and acceptance were transformed in to scores using SPSS and their mean is calculated with comparing test value $=3$

\section{Reliability Statistics}

Table 2: Reliability Statistics

\begin{tabular}{|c|c|}
\hline Cronbach's Alpha & N of Items \\
\hline 0.827 & 10 \\
\hline
\end{tabular}

The research instrument was tested for reliability and it has 0.827 Chronbach's alpha value.

\subsection{Demographic profile of the respondents}

\begin{tabular}{|c|c|c|c|}
\hline \multicolumn{2}{|c|}{ Demographic Factor } & \multirow{2}{*}{$\begin{array}{c}\begin{array}{c}\text { No. of. } \\
\text { Respondents }\end{array} \\
278 \\
\end{array}$} & \multirow{2}{*}{$\begin{array}{c}\begin{array}{c}\text { Percentage } \\
(\%)\end{array} \\
65.9 \\
\end{array}$} \\
\hline \multirow{3}{*}{ Gender } & Male & & \\
\hline & Female & 144 & 34.1 \\
\hline & Total & 422 & 100 \\
\hline \multirow{4}{*}{ Age } & Between $18 y r s$ to 25 yrs & 240 & 56.9 \\
\hline & Between $26 \mathrm{yrs}$ to $35 \mathrm{yrs}$ & 110 & 26.1 \\
\hline & Between $36 \mathrm{yrs}$ to $45 \mathrm{yrs}$ & 072 & 17.1 \\
\hline & Total & 422 & 100 \\
\hline \multirow{4}{*}{$\begin{array}{l}\text { Educational } \\
\text { Qualification }\end{array}$} & Graduate & 106 & 25.1 \\
\hline & Post Graduate & 306 & 72.5 \\
\hline & Professional & 010 & 02.4 \\
\hline & Total & 422 & 100 \\
\hline \multirow{6}{*}{ Income } & Less than Rs.20,000 & 212 & 50.2 \\
\hline & $\begin{array}{l}\text { Between Rs.20,001 to } \\
\text { Rs. } 40,000\end{array}$ & 136 & 32.2 \\
\hline & $\begin{array}{l}\text { Between Rs.40,001 to } \\
\text { Rs. } 60,000\end{array}$ & 028 & 06.6 \\
\hline & $\begin{array}{l}\text { Between Rs.60,001 to } \\
\text { Rs. } 80,000\end{array}$ & 028 & 06.6 \\
\hline & More than Rs.80,001/- & 018 & 04.3 \\
\hline & Total & 422 & 100 \\
\hline Occupation & Student & 200 & 47.4 \\
\hline
\end{tabular}




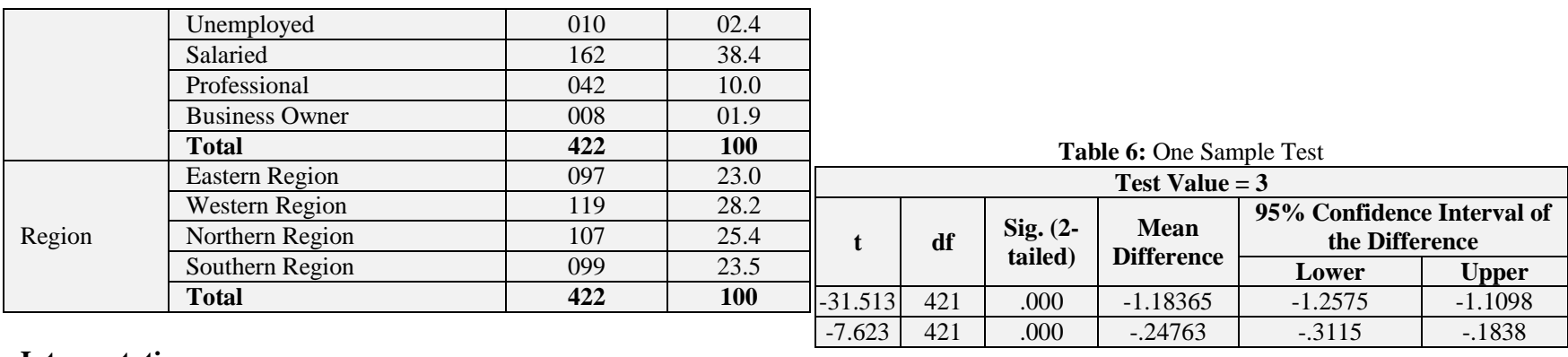

\section{Interpretation:}

From the above table 3, it is inferred that Out of 422 Respondents, $65.9 \%$ of the respondents belongs to the male category, whereas the remaining $34.1 \%$ of the respondents belongs to the female category. Also, Majority of the $56.9 \%$ respondents belongs to the Age group of between $18 \mathrm{yrs}$ to $25 \mathrm{yrs}$. In addition to that when we going through the Educational Qualification of the respondents, Majority $72.5 \%$ of them are Post Graduates. Out of the total respondents, Majority $50.2 \%$ of the respondent's income level ranges less an Rs.20, 000. Majority of the respondent belongs to the student community and salaried employees. Finally respondents data were been collected throughout all regions of India with the chance of equal preposition.

\subsection{Hypothesis Testing: No: 01}

Null Hypothesis: $\mathbf{H}_{1}=$ Social media users have negative perception

about safety and trust of financial transaction trough social media. $\left(\mathrm{H}_{0}=\mu>3\right)$

Alternate Hypothesis: $=\mathbf{H}_{\mathbf{A}}=$ Social media users have positive perception about safety and trust of financial transaction trough social media. $(\mathrm{H} 0=\mu>3)$

\section{Mean Variable Analysis}

As per the hypothesis one $\mathrm{H} 0=\mu>3$ and $\mathrm{H} 1=\mu<3$ where if the feasibility score is less than 3 , then hypothesis is accepted and if not hypothesis should be rejected.

As per the hypothesis two $\mathrm{HO}=\mu>3$ and $\mathrm{H} 1=\mu<3$ where if the perception score is less than 3 , then hypothesis is accepted and if not hypothesis should be rejected.

In order to test above mentioned hypothesis; variables measuring feasibility, perception and acceptance were transformed into feasibility score (FS), perception score and acceptance score (AS) respectively and composite mean was calculated to compare with test value. Mean score of these independent variables is as mentioned below in below Table.No.7.4.Mean Variable Analysis:

Table 4: Mean Variable Analysis Descriptive Statistics

\begin{tabular}{|l|l|c|}
\hline \multicolumn{3}{|c|}{ Descriptive Statistics } \\
\hline \multicolumn{1}{|c|}{$\mathrm{N}$} & Mean \\
\hline Feasibility Score- FS & 422 & 1.8164 \\
\hline Perception Score - PS & 422 & 2.7524 \\
\hline Acceptance Score -AS & 422 & 2.3436 \\
\hline Valid N (list wise) & 422 & \\
\hline
\end{tabular}

One Sample T-Test Analysis:

Table 5: One Sample Statistics

Table 5: One Sample Statistics
\begin{tabular}{|l|c|c|c|c|}
\hline & N & Mean & Std. Deviation & Std. Error Mean \\
\hline FS & 422 & 1.8164 & .77159 & .03756 \\
\hline PS & 422 & 2.7524 & .66735 & .03249 \\
\hline
\end{tabular}

\section{Interpretation:}

The Above Table 5. Shows the mean and standard deviation values of one sample t-test along with the standard error mean.

\section{One Sample T-Test Analysis:}

\section{Interpretation:}

The Value of two tail significance is less than $.05(\mathrm{p}<.05)$, as such the no difference between the mean is significant. The Output indicates that there is a no significant difference between Feasibility Score and Perception Score.

\subsection{Hypothesis Testing: No: 02}

Null Hypothesis: $\mathbf{H}_{2}=$ Acceptance score of financial transaction through social media platform independent of feasibility and perception of social media use.

Alternate Hypothesis: $=\mathbf{H}_{\mathrm{A}}=$ Acceptance score of financial transaction through social media platform is dependent of feasibility and perception of social media use.

Regression analysis is used to test this hypothesis and to find out dependency of acceptance score of financial transaction through social media platform on feasibility and perception of social media use and results are as:

Model Summary

\begin{tabular}{|c|c|c|c|c|c|}
\hline \multirow{2}{*}{ Model } & \multicolumn{5}{|c|}{ Change Statistics } \\
\cline { 2 - 6 } & R Square Change & F Change & df $^{\mathbf{1}}$ & df $^{2}$ & Sig. F Change \\
\hline 1 & $0.678^{\mathrm{a}}$ & 441.029 & 3 & 419 & .000 \\
\hline
\end{tabular}

a. Predictors: (Constant), PS, FS.

Interpretation:

From the above table, it is observed that $\mathrm{R}$ Square value is 0.678 and significant value of test is 0.000 hence, it is found that Acceptance score of financial transaction through social media platform is $67 \%$ dependent on feasibility and perception of social media use which is reliable to accept null hypothesis and reject alternate hypothesis.

\subsection{Hypothesis Testing: No: 03}

Null Hypothesis: $\mathbf{H}_{3}=$ Frequency of financial transaction through social media platform is independent of feasibility score and perception score of use.

Alternate Hypothesis: $\mathbf{=} \mathbf{H}_{\mathbf{A}}=$ Frequency of financial transaction through social media platform is dependent of feasibility score and perception score of use.

Regression Analysis is used to test this hypothesis and to find out dependency of frequency of financial transaction through social media platform on feasibility and perception of social media use and results are as:

\section{Model Summary}

\begin{tabular}{|c|c|c|c|c|c|}
\hline \multirow{2}{*}{ Model } & \multicolumn{5}{|c|}{ Change Statistics } \\
\cline { 2 - 6 } & R Square Change & F Change & $\mathbf{d f}^{1}$ & $\mathbf{d f}^{2}$ & Sig. F Change \\
\hline 1 & $0.539^{\mathrm{a}}$ & 245.041 & 3 & 419 & .000 \\
\hline
\end{tabular}

a. Predictors: (Constant), PS, FS

\section{Interpretation:}

From the above table, it is observed that $\mathrm{R}$ Square value is 0.539 and significant value of test is 0.000 hence, it is found that frequency of financial transaction through social media platform is $53.9 \%$ dependent on feasibility and perception of social media use which is reliable to accept null hypothesis and reject alternate hypothesis.

\subsection{Structural Equation Model}


Structural Equation Modeling (SEM) is a tool for analyzing multivariate data that has been long known in marketing to be especially appropriate for theory testing. Structural equation models go beyond ordinary regression models to incorporate multiple independent and dependent variables as well as hypothetical latent constructs that clusters of observed variables might represent. They also provide a way to test the specified set of relationships among observed and latent variables as a whole, and allow theory testing even when experiments are not possible. As a result, these methods have become ubiquitous in all the social and behaviora sciences MacCallum, R. C. \& Austin, J. T. ${ }^{[5]}$ Browne MW, Cudeck $\mathbf{R}^{[6]}$ study indicates the model fit can be checked by
RMSEA which is less than 0.08 has a good fit and less than 0.05 has a closer fit. (Chin and Todd 1995) research study proposed that for Goodness of Model Fit, where in Goodness of Fit Index (GFI) and Normed Fit Index (NFI) should be above 0.9 and Adjusted Good-Of-Fit Index (AGFI) should be above 0.8. Bentler PM $^{[7][8]}$, study suggest for Good Model Fit, whereas these Comparative Fit Index (CFI) should be greater than 0.9. The goodness of final model fit has been shown in table 7 . As per the various model fit statistics indicates that model was good fit.

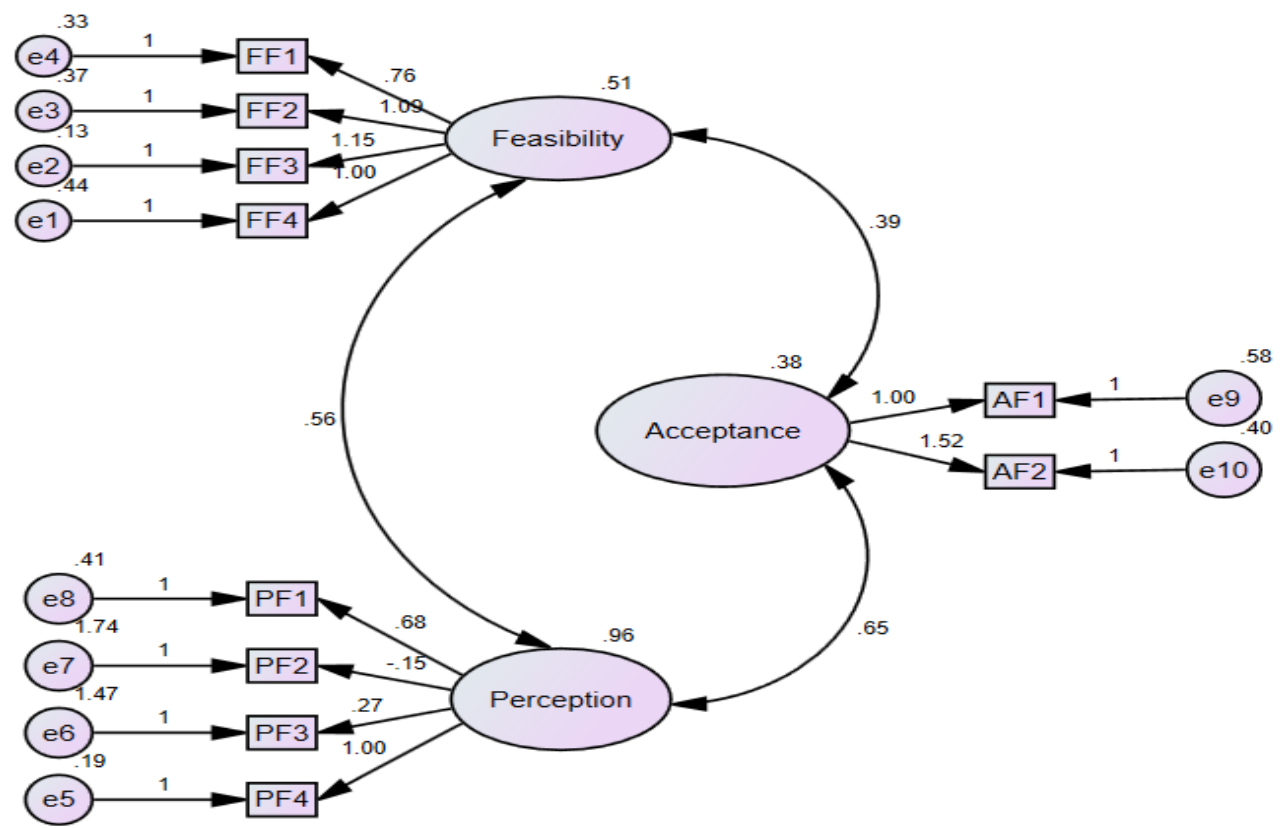

Fig.No.2. Structural Equation Model - Social Media Usage as a Digital Financial Platform

Table 7: Model Fit Statistics

\begin{tabular}{|l|c|c|}
\hline \multicolumn{1}{|c|}{ Goodness Of Fit Statistics } & $\begin{array}{c}\text { Observed } \\
\text { Value }\end{array}$ & $\begin{array}{c}\text { Values For } \\
\text { Good Fit }\end{array}$ \\
\hline Chi Square Value (CMIN) & 8.409 & $\geq 0$ \\
\hline Degree of Freedom (Df) & 2.3 & 2 to 5 \\
\hline Chi Square / Df (CMIN/Df) & 3.505 & $>0.9$ \\
\hline Goodness of Fit Index (GFI) & 0.987 & $<0.08$ \\
\hline Root Mean Square Error (RMSER) & 0.062 & $>0.9$ \\
\hline Adjusted Good of Fit Index (AGFI) & 0.953 & $>0.9$ \\
\hline Comparative Fit Index (CFI) & 0.989 & $>0.9$ \\
\hline Normed Fit Index (NFI) & 0.988 & \multicolumn{2}{|c|}{} \\
\hline
\end{tabular}

2] Sourav Mujumdar (2017), "Flipkart's Digital Drive - The ecommerce giant's digital payments foray PhonePe is a potential game changer", Forbes-India, Nov 23rd, 2017. http://www.forbesindia.com/article/column/flipkarts-digitaldrive $/ 48715 / 1$

[3] Richard Eldridge (2017), "How Social Media Is Shaping Financial Services", HuffPost Blog, 21st Jan 2017. https://www.huffingtonpost.com/richard-eldridge/how-socialmedia-is-shapi_b_9043918.html.

[4] Laurence Leyden (2017), "Getting Started With Your Core Banking Project", Digitalist 2017. https://www.digitalistmag.com/industries/getting-started-with-yourcore-banking-project-022464.

\subsection{Findings and Conclusion}

Ongoing through various experts view it's been understood that many managers strongly believe that all social media users are a group of next generation customers who were born during the explosion of digital technologies and they do have a precise understanding of these technologies but the real truth is that the number of users over 50 years in social media was predominately on the raising and increasing side.

These statistical data's can clearly explain the future of social media as a technological financial platform which plays a major role among the next generation customers. Structural Equation Model also portrays their characteristics relatively to their major need and importance in it. Hence, The Major Outcomes of the research study leads to the major implications, which it would certainly be useful for all of its stake holders in this upcoming modern and digital era.

\section{References:}

[1] Sunny Banerjea (2012), "Social Media in Financial Services", KPMG - International Cooperative (KPMG International), pp.01-16. https://www.kpmg.de/docs/Social-media-fs-12.pdf.

[5] MacCallum, R. C. \& Austin, J. T. (2000), "Applications of structural equation modeling in psychological research". Annual Review of Psychology, Vol.No.51, pp.201-226. https://doi.org/10.1146/annurev.psych.51.1.201.

[6] Browne MW, Cudeck R (1993), "Alternative Ways of Assessing Model Fit". In: Bollen K, Long J, editors. Testing Structural Equation Models. Sage; Newbury Park, CA: 1993. pp. 136-162.

[7] Bentler PM (1990), "Comparative Fit Indexes in Structural Models", Psychological Bulletin, Vol.No.107, pp.238-246. https://doi.org/10.1037/0033-2909.107.2.238.

[8] Bentler, Peter M. (1980), "Multivariate Analysis with Latent Variables: Causal Modeling," in Annual Review of Psychology, 31, 419 456. https://doi.org/10.1146/annurev.ps.31.020180.002223.

[9] Bagozzi, Richard P. (1980a), Causal Models in Marketing, New York: John Wiley \& Sons.

[10] Bagozzi, Richard P. (1980b), "On the Construct Validity of the Expectancy-Value Model of Attitude," Unpublished working paper, Massachusetts Institute of Technology. 
[11] Bagozzi, Richard P. (1980c), "A Holistic Methodology for Modeling Consumer Response to Innovation," unpublished working paper, Massachusetts Institute of Technology. 